\title{
A distal dimerization domain is essential for DNA-binding by the atypical HNF1 homeodomain
}

\author{
Tanguy Chouard, Marta Blumenfeld, Ingolf Bach, Joël Vandekerckhove ${ }^{1}$, Silvia Cereghini and \\ Moshe Yaniv* \\ Unité des virus oncogènes, UA 1149 du CNRS, Département de Biologie Moléculaire, Institut \\ Pasteur, 25 rue du Dr Roux, 75724 Paris cedex 15, France and 'Laboratorium voor Genetica, \\ Rijksuniversiteit Gent, B 9000 Gent, Belgium
}

Received March 8, 1990; Revised and Accepted August 8, 1990

EMBL accession no. $\times 54423$

\begin{abstract}
Hepatic Nuclear Factor 1 (HNF1, also referred to as LFB1, HP1 or APF) is a liver-specific transcription factor required for the expression of many hepatocyte specific genes. We report here the purlfication of this rat liver nuclear protein and the cloning of Its CDNA using a PCR-derived approach. Seven independent clones reveal 3 alternative polyadenylation sites and a unique open reading frame. Both a motlf homologous to the homeodomain and a distal dimerization domain are required for specific DNA binding. Sequence comparisons reveal several atypical features at key positions in the segment corresponding to helices III and IV of the Antaennapedia homeodomain as well as a potential 24 amino acid loop in place of the universal turn between hellces II and III. Together with Its property to dimerize in the presence or absence of DNA, these features place HNF1 as the prototype of a novel subclass of transcription factors distantly related to homeoprotelns.
\end{abstract}

\section{INTRODUCTION}

Transcriptional analysis of the albumin promoter has led to the identification of the cis-elements $(1,2)$ and the corresponding transacting factors $(3-5)$ that are required for efficient and hepatocyte-specific transcription. Mutations in the proximal element immediately upstream of the TATA motif cause the most drastic and most hepatocyte-specific effect on transcription (6, 7). The factor interacting with this site has been characterized in several laboratories $(8-11)$ as binding to proximal control regions in the promoters of many liver-specific genes as well as to several of their distal enhancer elements (reviewed in 12, 13). The consensus sequence derived from these binding sites, g/aGTTAATNATTAACc/a, is palindromic, although it is never fully symmetrical in its various natural occurences. The HNF1 target site is able to drive tissue-specific transcription of heterologous, ubiquitous promoters when cloned in both orientations or even as single or multimerized copies upstream of a TATA motif $(7,14-16)$. In the Xenopus laevis albumin promoter, the HNF1 target site seems to be the only functional element upstream of the TATA motif (10).

In vitro studies confirm the crucial role of HNF1 in hepatocytespecific transcription. Titration of HNF1 protein in rat liver nuclear extracts using an excess of its specific DNA target abolishes the transcription driven by liver-specific promoters containing the HNF1 site $(10,11,14)$. Furthermore, highly purified rat HNFI protein is sufficient to complement a spleen nuclear extract for the in vitro transcription of the mouse albumin promoter (17). We report, here, the isolation of cDNA clones coding for HNF1 and the preliminary mapping of its DNAbinding domain which reveals several atypical features.

\section{MATERIALS AND METHODS}

Purification and microsequencing of HNF1

The double stranded oligonucleotide PE56a (generated by annealing the following oligonucleotides : 5 ' TCGAGTGTGGTTAATGATCTACAGTTA-3' and 5'-TCGATAACTGTAGATCATTAACCACAC-3'), encompassing the HNF1 binding site of the rat albumin promoter, was phosphorylated and stepwise ligated to a Sepharose-bound oligonucleotide bearing a XhoI cohesive end (18), to generate a specific DNA-affinity chromatography medium carrying 50-75 $\mu \mathrm{g} \mathrm{DNA} / \mathrm{ml}$ gel. HNF1 purification was monitored by a band-shift assay using 5 '-end-labeled PE56a. Liver nuclear extracts were prepared from 150 rats as described (11), except that the second sucrose cushion was omitted; proteins were resuspended in Elution Buffer (EB: $20 \%$ glycerol, $20 \mathrm{mM}$ hepes $\mathrm{pH} 7.9,0.5 \mathrm{mM}$ EDTA, $0.5 \mathrm{mM}$ DTT, O.5 mM PMSF, $12 \mathrm{mM} \mathrm{MgCl}_{2}, 1 \mu \mathrm{g} / \mathrm{ml}$ pepstatin, leupeptin and aprotinin) to a conductivity lower than that of 0.15 $\mathrm{mM} \mathrm{KCl}$ in EB and loaded on five $200 \mathrm{ml}$ columns of heparin Ultrogel (IBF). HNF1 containing fractions were eluted with 0.35 $\mathrm{M} \mathrm{KCl}$, diluted with $\mathrm{EB}$ to $0.3 \mathrm{M} \mathrm{KCl}$ supplemented with polydIdC (15 $\mu \mathrm{g} / \mathrm{mg}$ protein) and O.1\% NP40 and loaded on PE56aDNA-affinity columns ( $20 \mathrm{ml}$ total volume). Columns were washed with $0.3 \mathrm{M} \mathrm{KCl}$ and $\mathrm{HNF} 1$ activity was eluted at 0.6 $\mathrm{M} \mathrm{KCl}$, with a yield of $20 \%$ and a purification factor of 6600 fold, relative to nuclear extracts. $30 \mathrm{ml}$ of pooled fractions

* To whom correspondence should be addressed 
containing $25-30 \mu \mathrm{g}$ of $87-93 \mathrm{kDa} \mathrm{HNF} 1$ were concentrated by lyophilisation to $10 \mathrm{ml}$ and dialysed against $10 \mathrm{mM}$ ammonium acetate containing $0.01 \%$ SDS before further concentration to $300 \mu \mathrm{l}$; the protein was electrophoresed on an SDS-10\% polyacrylamide gel (19) and electroblotted onto a polyvinylidene



Figure 1: Analysis of affinity-purified HNF1. Dimers stabilized by S-S bonds. $10 \mathrm{ng}$ of labelled PES6a oligonucleotide, in which several thymine residues had been replaced by bromodeoxyuridine residues, were incubated with $10 \mu \mathrm{l}$ of affinity-purified fraction and complexes were resolved by preparative $5 \%$ native PAGE (lane 1); proteins were UV-crosslinked to DNA and two bands (U and $\mathrm{L}$ for upper and lower bands respectively) separately cut and analyzed by $10 \%$ SDS-PAGE in reducing (lanes 2,$3 ; 0.1 \% \beta$-mercaptoethanol) or nonroducing conditions (lanes 4, 5). The estimated molecular weights of UV-crosslinked peptides should be reduced by $10-15 \mathrm{kDa}$, due to the contribution of the PE-56a oligonucleotide (11). The fraction corresponding to the peak of DNA-binding activity was analyzed by silver-stained $8 \%$ SDS-PAGE in reducing (lane 7 ) or nonreducing conditions (lane 6). $\mathrm{m}$ : markers for molecular weights (given in $\mathrm{kDa}$ ). difluoride membrane (PVDF); the amidoblack stained 87-93 kd HNF1 band was cut out, digested in situ with trypsin and the eluted tryptic peptides were fractionated by Reversed Phase HPLC Chromatography followed by gas-phase amino acid sequence analysis as previously described (20 and references therein).

\section{Production of a nondegenerate DNA probe using polymerase chain reaction (PCR)}

Enzymatic DNA amplifications with Taq DNA polymerase were performed in the buffers indicated by Saiki et al. (21) using $10 \mathrm{ng}$ of oligo-dT primed cDNA from Fao cells (see below) and $1 \mu \mathrm{g}$ each of oligonucleotides $\mathrm{C} 1$ or $\mathrm{C} 3$ and D2 or D4 (see text and Figure 2). After 50 cycles of primary amplification (one cycle $=15^{\prime \prime}$ at $94^{\circ} \mathrm{C}, 1^{\prime}$ at $60^{\circ} \mathrm{C}, 1^{\prime}$ at $72^{\circ} \mathrm{C}$ ) a $10 \%$ aliquot was futher amplified for 50 cycles and amplification products were analyzed on a $20 \%$ polyacrylamide gel. DNA of samples displaying only the expected amplified band ( $47 \mathrm{bp}$ ) in addition to the singlestranded primers was directly extracted with phenol-chloroform, phosphorylated, blunt-end ligated to a Bluescribe vector linearized with Smal and sequenced. A 41-mer oligonucleotidic probe (CD41, see Figure 2) was derived from the sequence data.

\section{Preparation and screening of cDNA libraries}

An amplified $\lambda$-gt $10 \mathrm{cDNA}$ library (oligo-dT primed) from rat hepatoma Fao cells treated with cycloheximide was prepared according to standard procedures (22) and was screened with 5 '-end-labeled CD41 and A15 probes (Figure 2). Hybridizations were performed in $6 \times$ saline sodium citrate (SSC), $1 \times$ Denhardt's solution, $50 \mu \mathrm{g} / \mathrm{ml}$ tRNA, $0.05 \%$ sodium pyrophosphate at $42^{\circ} \mathrm{C}$; washes were done at $55^{\circ} \mathrm{C}$ in $1 \times \mathrm{SSC}$. Inserts of positive clones were subcloned in a Bluescribe vector and sequenced on both strands by the dideoxynucleotide method modified for doublestranded DNA $(23,24)$ using successive primers.

\section{Construction of HNF1 expression vectors}

Full length HNF 1 cDNA was obtained as follows: the A4 clone was digested with SacI, treated with T4 DNA-polymerase and then digested with MluI to generate an MluI-SacI HNF1 fragment with a blunt SacI end (nt 200-2240, Figure 4); the 5' part of HNF1 cDNA was synthesized by reverse transcription of rat liver

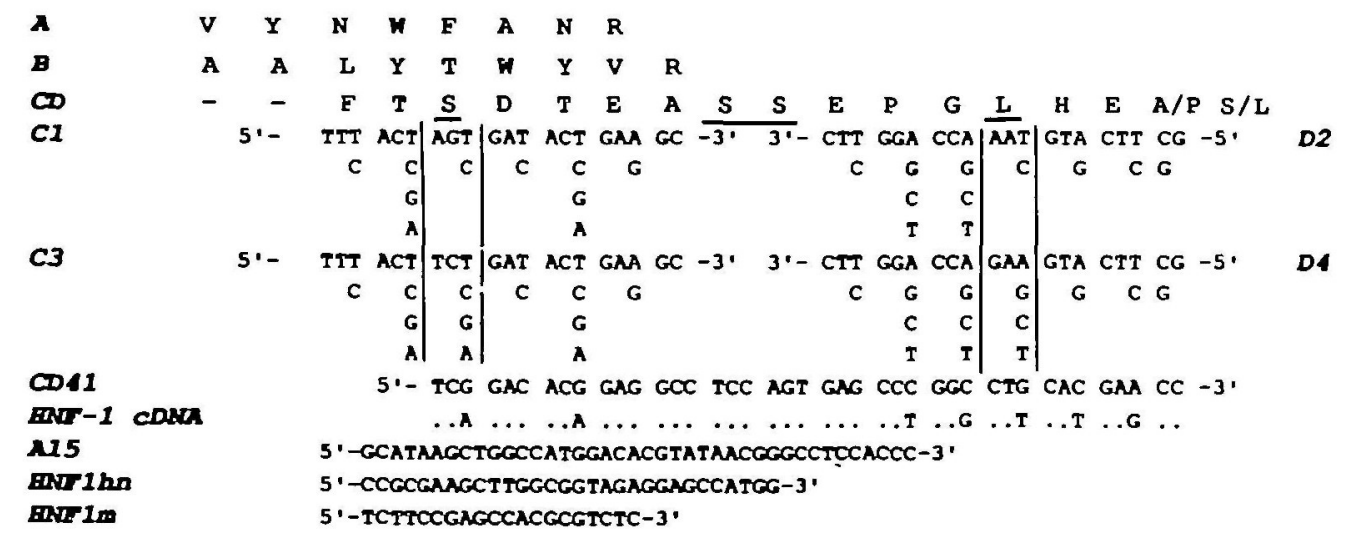



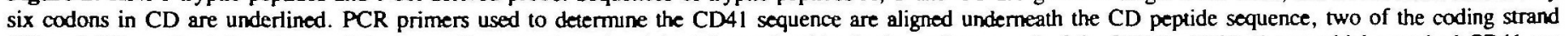



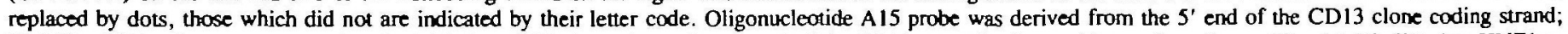

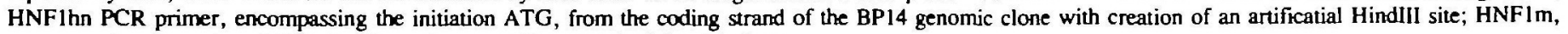
encompassing the unique MluI site, from the noncoding strand of the A4 clone. 
total RNA $(10 \mu \mathrm{g})$ using a primer complementary to nt $230-250$ (Figure 4); the purified cDNA then served as template to generate a PCR fragment using HNF1hn and HNFlm oligonucleotides (Figure 2) and the $241 \mathrm{bp}$ fragment thus obtained was digested at the HindIII and MluI sites included in the PCR primers. Both $3^{\prime}$ and $5^{\prime}$ cDNA fragments were ligated to an HindIII/HpaI digested pRSV-CAT vector (25), thus generating the pRSVHNF 1 construct. pRSV-HNF1 was digested partially with NcoI and then with BamHI to obtain a 2369 bp fragment encompassing the segment 1-2240 of the HNF1 sequence (Figure 4) followed by the 129 bp Hpal-BamHI segment from pRSV-CAT. This fragment was cloned between the $\mathrm{NcoI}$ and BamHI sites of a (T7 promoter- $\beta$ globin leader)-vector, derived from pGEM1 (provided by Dr. R. Treisman), thus putting the whole HNF1 coding sequence in frame with the $\beta$ globin initiator ATG (pT7 $\beta \mathrm{H}$ plasmid).

HNF1 deletion vectors were constructed as follows: the 774 bp Smal fragment from pT7 $\beta \mathrm{H}$ was cloned in frame with the

A
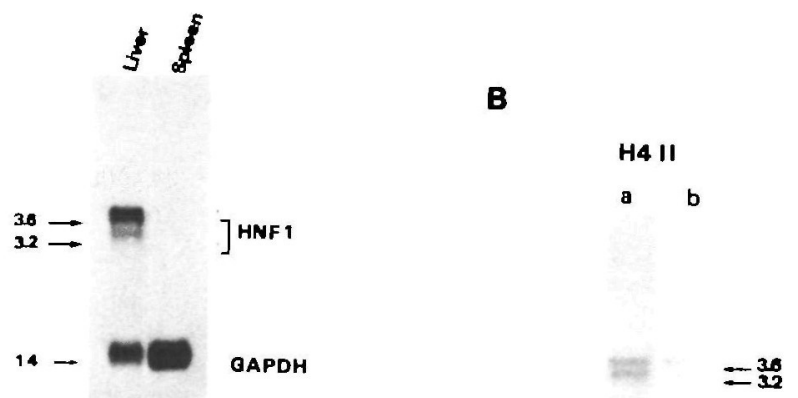

$\mathrm{C}$

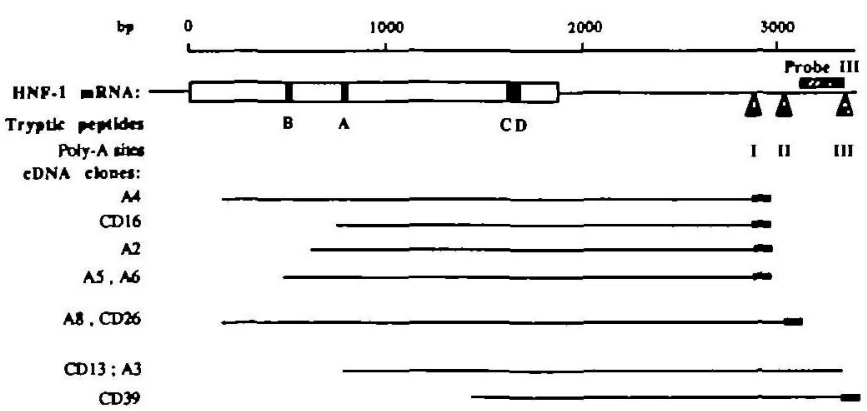

Figure 3A: Northem blo analysis of HNF1 transcripts. $3 \mu \mathrm{g}$ of rat liver or spleen poly A+RNA were fractionated and hybridized with a mixture of full length HNF1 (clone CD26, Figure 3C) and GAPDH probes. Arrows to the left indicate the estimated size of the different bands. B: Northem blot analysis of alternatuve polyadenylation sites usage. In lane b, $12.5 \mu \mathrm{g}$ of total RNA from H4II cells were hybridized with an HNFI antisense RNA probe specific for transcripts of group III (see text; Probe III: nt 3158-3397, Figure 3C); after the final high stringency wash, the blot was rehybridized with a full length HNFI cDNA probe (lane a). C: Schematic map of HNF1 cDNA clones presenting three polyadenylation sites. The extent of each of the seven independent HNFI cDNA clones is indicated relative to the combined sequence of the HNFI mRNA in front of the list of the corresponding redundant clones. The HNFI open reading frame is indicated by a box; tryptic peptides are shown in black. PolyA tails are indicated by a black box at the end of each clone and the three polyadenylation sites included in the longest sequence are indicated by triangles. The group III specific probe (Probe III) is indicated by a hatched box. first ATG in an Ncol digested pT7 $\beta \mathrm{H}$ vector repaired with the Klenow enzyme, thus generating pT7 $\beta \mathrm{H}-34 / 291 ; \mathrm{pT} 7 \beta \mathrm{H}-\Delta 18 / 53$ was obtained by Xhol digestion of pT7 $\beta \mathrm{H}$ followed by repair with the Klenow enzyme and auto-ligation; $\mathrm{pT} 7 \beta \mathrm{H}-\Delta 34 / 208$ was constructed by digestion of $\mathrm{pT} 7 \beta \mathrm{H}$ with ApaI, further treatment with T4 DNA polymerase and auto-ligation.

\section{In vitro transcription and translation}

Sense RNA was synthesized in vitro using 10 units of T7-RNA polymerase (Stratagene transcription kit) and $1 \mu \mathrm{g}$ of DNA templates linearized as follows: the $\mathrm{T} 7 \beta \mathrm{H}-\mathrm{wt}, \mathrm{T} 7 \beta \mathrm{H}-1 / 390$, $\mathrm{T} 7 \beta \mathrm{H}-1 / 281$ and $\mathrm{T} 7 \beta \mathrm{H}-1 / 264$ transcripts were generated after digestion of $\mathrm{pT} 7 \beta \mathrm{H}$ with BamHI, AatII, BalI and AccI respectively. The $\mathrm{T} 7 \beta \mathrm{H}-34 / 291, \mathrm{~T} 7 \beta \mathrm{H}-\Delta 18 / 53$ and $\mathrm{T} 7 \beta \mathrm{H}-$ $\Delta 34 / 208$ transcripts were obtained after digestion with BamHI of the corresponding deletion plasmids.

After $1 / 2$ hour incubation at $37^{\circ} \mathrm{C}$, phenol/chloroform extraction and ethanol precipitation, the synthesized RNA was resuspended in $20 \mu \mathrm{l}$ of water and $2 \mu \mathrm{l}$ was used for the in vitro translation with a rabbit reticulocyte lysate system (Amersham). The reaction mixture $(15 \mu \mathrm{l})$ included $12 \mu \mathrm{l}$ of the cell lysate and $1 \mu \mathrm{l}$ of diluted $\left[{ }^{35} \mathrm{~S}\right] \mathrm{L}$-methionine $(<1000 \mathrm{Ci} / \mathrm{mmol}$, $1 \mathrm{mmol} / \mathrm{ml}$ ). The translation was carried out for 1 hour at $30^{\circ} \mathrm{C}$, and quantity and quality of the products were checked by counting TCA-insoluble ${ }^{35} \mathrm{~S}$ and by SDS-PAGE.

\section{Gel retardation assays, SDS-PAGE and UV-crosslinking experiments}

Gel retardation assays and UV-crosslinking experiments with liver proteins were performed as previously described (11), without any competitor DNA in the case of affinity-purified fractions.

For each in vitro translated protein, the volume indicated in the legend for Figure 5A was preincubated for $10 \mathrm{~min}$ on ice with sonicated salmon sperm DNA at a ratio of $0.5 \mu \mathrm{g} / \mu \mathrm{l}$ translation mixture and with competitor oligonucleotide where mentioned, in $20 \mu \mathrm{l}$ of binding buffer containing $10 \mathrm{mM}$ Hepes, $4 \mathrm{mM} \mathrm{MgCl}_{2}, 0.1 \mathrm{mM}$ EDTA, $4 \mathrm{mM}$ spermidine, $15 \%$ glycerol. After addition of $1 \mathrm{ng}$ of ${ }^{32}$ P-labelled PE56 oligonucleotide probe, mixtures were further incubated for 10 $\mathrm{min}$ on ice and then analyzed by $5 \%$ PAGE in $0.25 \times$ TBE. The gel was dried and exposed to two sheets of X-ray film with intensifying screen at $-80^{\circ} \mathrm{C}$. The film closest to the gel shows both ${ }^{35} \mathrm{~S}$ and ${ }^{32} \mathrm{P}$ signals and the second one only ${ }^{32} \mathrm{P}$ intensified signals. Figure 5A shows only the pattern of the second film. SDS-PAGE were done according to Laemmli (19) and, in the case of in vitro translated protein analysis, treated for fluorography (22) before exposure.

\section{Northern blot analysis}

Total RNA from rat liver, spleen or H4II cells was extracted using the guanidium thiocyanate- $\mathrm{CsCl}$ method (26). Poly $\mathrm{A}+$ RNA was isolated by oligo dT cellulose chromatography (22), electrophoresed through $1.2 \%$ agarose-2.2 $\mathrm{M}$ formaldehyde gels and transferred to a Hybond $\mathrm{N}$ membrane (Amersham). RNA markers (0.24-9.5 kb; BRL) were run in parallel and visualized under UV. cDNA inserts were isolated from agarose gels, labelled by random priming to a specific activity of $3-7 \times 10^{8}$ $\mathrm{cpm} / \mu \mathrm{g}$ for HNF1 and $1 \times 10^{7} \mathrm{cpm} / \mu \mathrm{g}$ for GAPDH and used as probes. Hybridization was performed at $42^{\circ} \mathrm{C}$ in $50 \%$ formamide, $5 \times$ SSPE, $5 \times$ Denhardt with the ${ }^{32} \mathrm{P}$-labelled probe for 24 hours. The membranes were washed at $60^{\circ} \mathrm{C}$ with $5 \times$ SSC, $0.25 \%$ SDS 


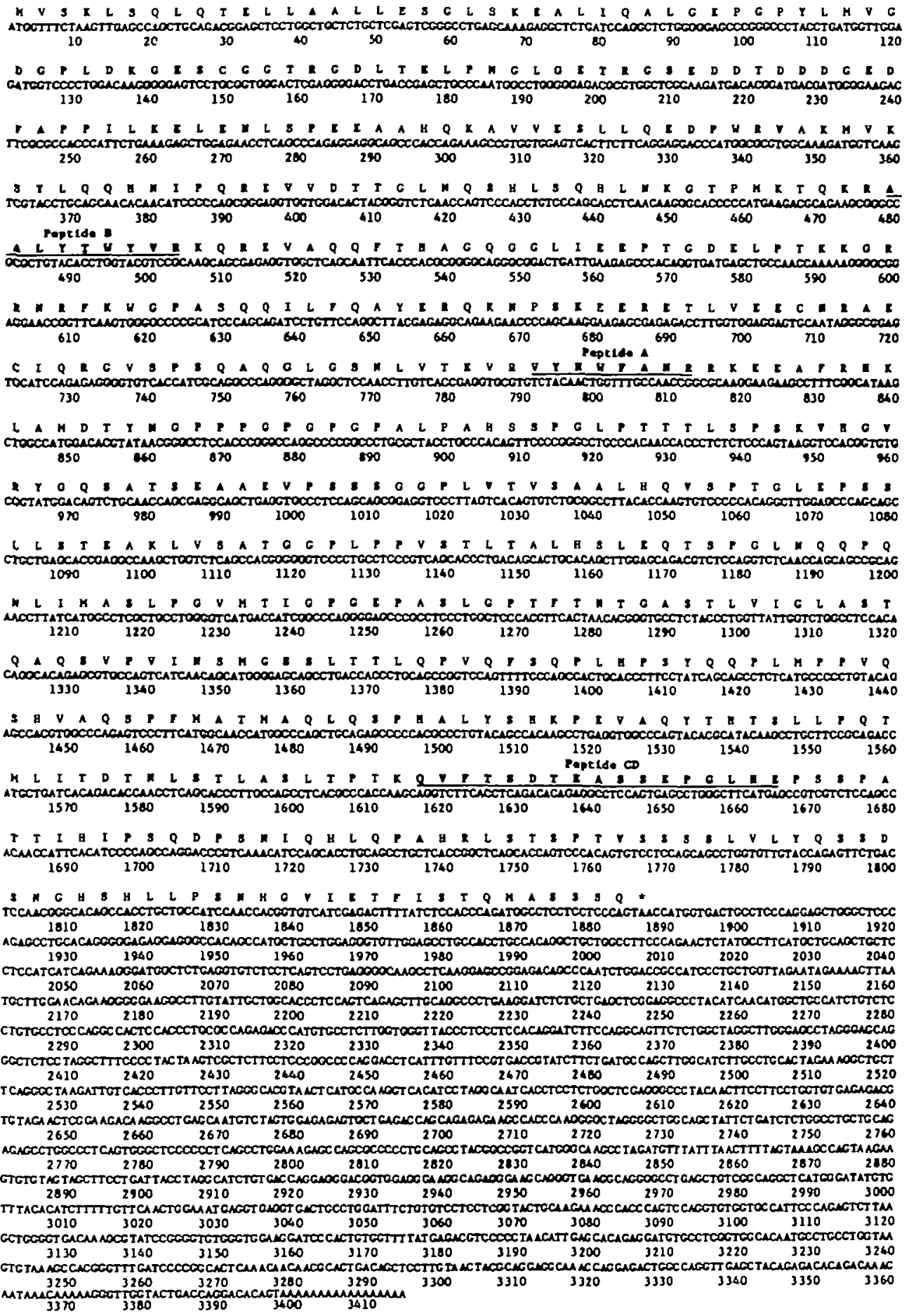

Figure 4: HNF1 cDNA sequence. Amino acids are given in single letter code above the nucleotide sequence. The numbering adopted, for both the nucleotide and the amino acid sequences, is initiated at the first codon of the HNF1 open reading frame (see text). Underline bold regions indicate tryptic peptides that were sequenced. * indicates the first nonsense codon.

and $0.1 \times$ SSC, $0.25 \%$ SDS. Alternatively, an HNF1 antisense RNA probe (nt 3158-3397) was prepared by in vitro transcription with T7 RNA polymerase of a BamHI digested CD13 clone (Figure 3C). Membranes were hybridized in 50\% formamide, $5 \times \mathrm{SSC}, 5 \times$ Denhardt at $52^{\circ} \mathrm{C}$ for $16 \mathrm{~h}$. and washed at a final stringency of $0.1 \times \mathrm{SSC}$ at $74^{\circ} \mathrm{C}$ for $1 \mathrm{~h}$.

\section{RESULTS}

Native HNF1 forms dimers in the presence or absence of its DNA-target

HNF1 protein was purified from rat liver in a three step procedure: preparation of nuclear extracts, chromatography on heparin 
Ultrogel and specific DNA-affinity column as described in Materials and Methods. The peak of HNF1 DNA-binding activity produced two complexes in gel retardation assay (Figure 1, lane 1: arrows $\mathrm{U}$ and $\mathrm{L}$ ) and displayed a major $87-93 \mathrm{kDa}$ protein, a $72 \mathrm{kDa}$ polypeptide and several minor polypeptides (Figure 1, lane 7). To determine which of these polypeptides directly interacted with DNA, we performed UV-crosslinking experiments, in which ${ }^{32} \mathrm{P}$-labelled oligonucleotide containing BrdU residues was covalently linked to the proteins in the retardation gel, before the upper and lower band were excised and run on a SDS-polyacrylamide gel. The upper complex gave rise to a roughly $100 \mathrm{kDa}$ band corresponding to the $87-93 \mathrm{kDa}$ protein linked to the $15 \mathrm{kDa}$ oligonucleotide, which is in agreement with the molucular weight previously reported for HNF1 $(27,11,12,17)$. The heterogeneity of the $87-93 \mathrm{kDa}$ band (lane 7) is probably caused by the glycosylation of HNF1 (see below). The lower complex gave rise to the same $100 \mathrm{kDa}$ band in addition to faster migrating species, likely to be proteolyzed chains since the yield of this lower retarded band increased during the purification procedure. The fact that the HNF1 binding site was almost palindromic suggested a hypothesis in which the upper complex would contain two intact $87-93 \mathrm{kDa}$ polypeptide chains and the lower band one intact and one partially degraded chains; the profile obtained in lanes 2 and 3 is compatible with this hypothesis. Analysis of the UV-crosslinked DNA-protein complexes in nonreducing conditions gave slower migrating bands, suggesting that HNFl might either associate with another polypeptide chain or form dimers covalently linked by S-S bonds (Figure 1, lanes 4 and 5). This interaction appeared to be specific since the same patterns were observed whether crude liver nuclear extracts or various purified fractions were used (data not shown). Further support for potential dimerization came from the observation that a major fraction of the 87-93 $\mathrm{kDa} \mathrm{HNFl}$ band ran as a $180 \mathrm{kDa}$ species under nonreducing conditions (Figure 1, lane 6). In addition, this suggested that the protein might preexist as a dimer in the absence of DNA ; neither addition of specific or unrelated DNA nor irradiation with UVlight increased the yield of dimerization observed in lane 6 (not shown). These observations were further strengthened using cloned HNF1 (see below). Gel retardation assays performed in the presence of different reducing agents, indicated that $\mathrm{S}-\mathrm{S}$ bond formation was not required for DNA-binding in vitro (data not shown), nevertheless, the factor might still need to dimerize for this purpose.

In order to obtain protein sequence data for the $87-93 \mathrm{kDa}$ chain, 150 pmoles were further purified by SDS-PAGE, since no other polypeptide was visible on two-dimensional gels at the same molecular weight level (not shown), then transferred to a PVDF membrane and digested in situ with trypsin. The tryptic peptides were fractionated on reversed phase HPLC and submitted to amino acid sequence analysis. The three sequences obtained are listed in Figure 2. Peptides A and B were used to derive redundant oligonucleotides for direct screening of cDNA libraries from rat liver or hepatoma cell lines. After several unsuccessful attempts, we turned to a PCR-derived approach to get better probes for HNF1.

\section{Use of PCR to generate a unique probe for HNF1}

From the longest peptide $(C D)$, four degenerate primers, two of the coding strand ( $\mathrm{Cl}$ and $\mathrm{C} 3$ ) and two of the noncoding strand (D2 and D4), were designed to reduce the high degeneracy due to serine and leucine residues (see Figure 2). These oligonucleotides were used in an enzymatic amplification on Fao cells cDNA, followed by cloning and sequencing of the expected $47 \mathrm{bp}$ PCR-amplified fragment. The nucleotides coding for the alanine and the two central serine residues of the $\mathrm{CD}$ peptide were thus unambiguously determined and a 41-mer nondegenerated probe was synthesized according to this sequence data (CD41 in Figure 2).

Since the $C$ and $D$ primers were highly degenerate (respectively 512 and 1024 mixed sequences) and PCR is a primer-limiting procedure, only about $1 \%$ of the $47 \mathrm{bp}$ amplified fragments that were visible on a gel might display the exact HNF1 sequence. The remaining must contain some mismatches mainly in the ends of the fragments, since elongation by Taq-DNA-polymerase requires a better annealing at the $3^{\prime}$ end of the primers. The nucleotides that were actually wrong in the single PCR fragment that we sequenced as compared to the final cDNA sequence are indicated in Figure 2.

Seven independent HNF1 cDNA clones display three polyadenylation sites and a single open reading frame

With the CD41 probe, we screened $10^{6}$ clones of a $\lambda$-gt 10 cDNA library prepared from rat hepatoma Fao cells (28), treated with cycloheximide to increase the representation of potentially unstable transcripts (29). We first isolated 3 partial cDNA clones (CD13, CD16, CD39); one of them (CD13) included the two others. A 45 bp probe (A15, Figure 2) from the most 5' region of this clone was synthesized and used to screen the same library. Seven new clones (A-clones and CD26) were isolated that were also positive with CD41. The structure of the ten clones including three pairs of identical ones is described schematically in Figure $3 \mathrm{C}$.

The total length of the combined nucleotide sequence (CD26 and the $3^{\prime}$ end of CD39 without the oligoA tail) was 3205 bases. The cDNA clones could be ordered in three groups (I, II, III, see figure $3 \mathrm{C}$ ) according to the position of their polyA tails relative to the combined sequence. When these clones were used to probe Northern blots with rat liver polyA RNA, a minor and a major species of 3.2 and $3.6 \mathrm{~kb}$ respectively were detected (figure 3A). Hence, our longest clone could not cover the entire length of the $3.6 \mathrm{~kb}$ mRNA and was probably missing a few hundred base pairs.

In addition, using a probe derived from the most $3^{\prime}$ sequence of clones of the group III, only the $3.6 \mathrm{~kb}$ species was detected, thus demonstrating that more than one polyadenylation site were actually used in vivo (Figure 3B). Examination of the sequences upstream of the polyA tails found in the three groups of clones revealed three possible alternative polyadenylation signals. The four independent clones of group I utilize the AGTAAA sequence at position 2864 (numbering of the figure 4 , see below) with a polyA chain 14 to $16 \mathrm{nt}$ downstream; the single clone of group II might use the AATGAG sequence at position 3027 with a polyA chain $17 \mathrm{nt}$ downstream; finally, the two clones of group III utilize the AATAAA sequence at position 3361 with a polyA chain $31 \mathrm{nt}$ downstream (30). The Northern blot analysis suggested that, in rat liver, the most $3^{\prime}$ site is used predominantly in rat liver. The situation was different in rat hepatoma cell lines (S.C., unpublished observations).

Conceptual translation of the cDNA sequence revealed a single open reading frame of 564 triplets, followed by a long nontranslated region. The open reading frame included peptides A, B and CD (underlined in figure 4) as well as two additional peptides that were not separated by the HPLC and gave short 

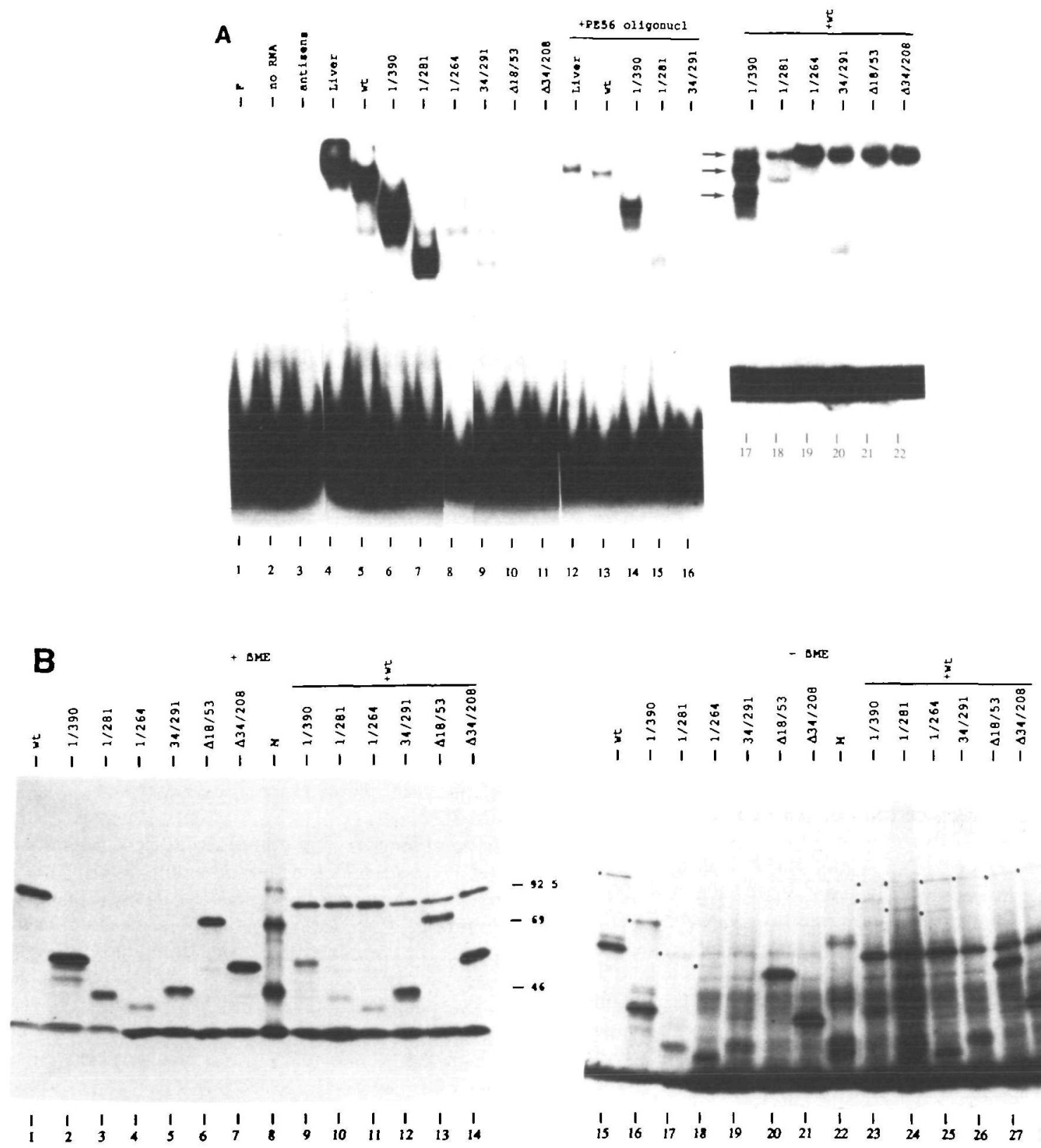

Figure 5: Functional mapping of the HNFI protein. A: In vitro translated HNFl analyzed by Band-shift assay. 1 ng of ${ }^{32} \mathrm{P}$-labelled PES6a probe was incubated as described in Materials and Methods with $1 \mu \mathrm{g}$ of rat liver nuclear proteins (lanes 4, 12) or with in vitro products of following constructions, in absence (lanes $1-11$ and 17-22) or presence of $9 \mathrm{ng}$ of unlabelled PE56a as competitor (lanes 12-16); the respective volumes of translation mixture used in binding assay and lanes in the Figure are indicated in paranthesis: no proteins (lane 1); reticulocyte lysate incubated without exogenous RNA (1 $\mu$, lane 2); antisens HNF1 RNA (1

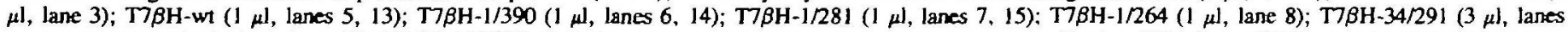

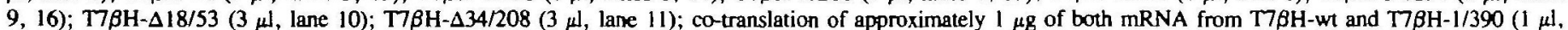

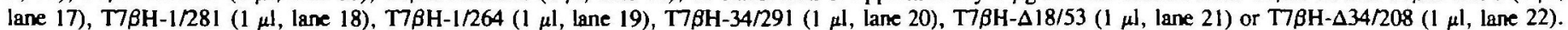
Band-shift assay were performed as described in Materials and Methods. Note that the band visible in lane 2 is common to all lanes where in vitro translated proteins were used and is due to a reticulocyte DNA-binding activity. Arrows to the left of lane 17 indicate the positions, from top to bottom, of wilt type homodimers, heterodimers and T7 $\beta \mathrm{H} 1 / 390$ homodimers. B: In virro translated HNFI analyzed by SDS-PAGE. $2 \mu 1$ of translation mixtures were diluted with $8 \mu$ l of water, left 1 hour at room temperature, mixed with $10 \mu \mathrm{l}$ of Laemmli's sample buffer (19) in presence (lanes 1-14) or absence (lanes 15-28) of 0.1\% $\beta$-mercaptoethanol and separated on two identical SDS-8\%-polyacrylamide gels that were subsequently autoradiographed for ${ }^{35}$ S-met-labelled protein detection. In the translation or co-translation reactions, approximately $1 \mu \mathrm{g}$ of mRNA from each of the following constructions were used and the respective lanes on gels are indicated in paranthesis: $\mathrm{T} 7 \beta \mathrm{H}$-wt (lanes 1, 15); $\mathrm{T} 7 \beta \mathrm{H}-1 / 390$ (lanes 2, 16); $\mathrm{T} 7 \beta \mathrm{H}-1 / 281$ (lanes 3, 17); $77 \beta \mathrm{H}-1 / 264$ (lanes 4, 18); $77 \beta \mathrm{H}-34 / 291$ (lanes 5,19 ); T7 $\beta \mathrm{H}-\Delta 18 / 53$ (lanes 6,20 );

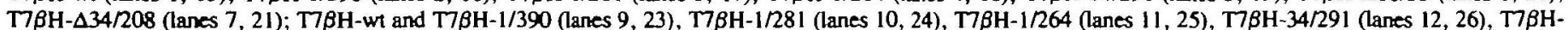
$\Delta 18 / 53$ (lanes 13,27 ) or $T 7 \beta \mathrm{H}-\Delta 34 / 208$ (lanes 14,28 ). ${ }^{14} \mathrm{C}$-labelled molecular weight markers $(92.5,69,46$ and $27 \mathrm{kDa}$; Amersham) were loaded in lanes 8 and 22. Dots on the left of bands on the autoradiogram indicate the homo- or hetero-dimers. Since an excess of intact protein was used in lanes $9-11$ and $23-25$, we do not detect homodimers of truncated proteins in these experiments. 
mixed sequences; all were preceded by arginine or lysine residues as expected for tryptic peptides. The first methionine in this open reading frame was in the 54th position (amino acid no. 118 in Figure 4), thus generating a polypeptide of 511 amino acids with a molecular weight of $54.7 \mathrm{kDa}$, probably too short when compared with the $87-93 \mathrm{kDa}$ protein that we purified. The absence of the initiation ATG in the cDNA clones was confirmed by analysis of a genomic clone (BP14) obtained by screening a rat library with a cDNA probe. The sequence of this clone partially overlapped the $5^{\prime}$ sequence of the cDNA clones. The first ATG codon preceded by a nonsense codon in phase was located 192 nucleotides upstream of our cDNA 5' end (I.B., unpublished results). Using a PCR primer overlapping this putative initiation codon and a second primer encompassing a unique MluI restriction site in our cDNA sequence (respectively HNF1hn, and HNF1m in Figure 2), we amplified a 241 bp fragment from a rat liver cDNA preparation, thus making sure that there was no splicing event within the first 192 coding base pairs. This was confirmed by cloning and sequencing of the PCR fragment. This sequence, combined with that of the CDNA clones, gives rise to an open reading frame encoding a polypeptide of 628 amino acids with a calculated molecular weight of $69 \mathrm{kDa}$ (see Figure 4). This sequence is virtually identical to recently published cDNA sequence for the LFB1 rat liver factor that was purified as a $45 \mathrm{kDa}$ protein : the exceptions are $1 \mathrm{nt}$ in the codon no. 434 , coding for a valine in both sequences, and $7 \mathrm{nt}$ in the noncoding region (31). A partial cDNA sequence of rat HNF1 was recently published by another group (32).

In vitro translated HNF1 requires a motif homologous to the putative recognition helix of the homeodomain for specific DNA-binding

To confirm that the cDNA we obtained coded for a protein that could indeed bind specifically to the albumin proximal element, we inserted its complete coding sequence in a pGEM1 derived vector and synthesized $\mathrm{HNF} 1$ by in vitro transcription and translation. The ${ }^{35} \mathrm{~S}$-met-labelled protein was analyzed by both a gel retardation assay and SDS polyacrylamide electrophoresis. When incubated with its specific DNA-binding site as probe (PE56a), in vitro translated HNFl gave rise to a complex that was specifically displaced by the homologous oligonucleotide (see lanes 5 and 13 in Figure 5A) but not by a mutated HNF1 DNA target (DS34 (11); not shown), thus demonstrating that our cDNA clone actually encoded the activity that had been purified from rat liver. In vitro translated HNF1 had an apparent molecular weight of $80 \mathrm{kDa}$, lower than that observed for the purified rat liver protein ( $87-93 \mathrm{kDa}$; Figure 1, lane 7, Figure 5A, lanes 4 and 5 and $5 B$ ) and these variations are likely to be due to the glycosylation of HNF1 (17 and our unpublished data). Examination of the complete amino acid sequence of HNF1 (Figure 4) reveals essentially two domains separated by a flexible junction rich in prolines and glycines (residues 288 to 297). The amino acid composition of the two domains is clearly different suggesting that they could have evolved separately. General features of the HNFl protein primary sequence are schematically represented in figure $6 \mathrm{~A}$.

The sequence VYNWFANR (residues V264 to R271) of peptide A matches the consensus sequence I/V-WF-NRR highly conserved in the putative DNA-recognition helix of homeodomains (36). Comparison of the HNFl sequence and homeoboxes identified to date is discussed below. To check whether this homology was functionally relevant, we analyzed the effect of progressive C-terminal deletions on HNF1 DNAbinding. Figure 5A shows that HNFl can still bind DNA specifically when the whole $\mathrm{C}$-terminal domain has been deleted (deletions T7 $\beta \mathrm{H}-1 / 390, \mathrm{~T} 7 \beta \mathrm{H}-1 / 281$; Figure 5A, lanes 6 and 7 resp.) but not when further deletion removes a short segment containing the putative recognition helix (deletion $\mathrm{T} 7 \beta \mathrm{H}-1 / 264$; Figure 5A, lane 8). Thus, the C-terminal end of the HNF1 DNAbinding domain is localized within the 17 amino acids 265 to 281 .

The HNF1 homeodomain is unable to bind specifically to its DNA target in the absence of a distal dimerization domain

In order to map the N-terminal end of the HNF1 DNA-binding domain, we constructed deletions using different restriction sites. The N-terminal domain encoded by the longest SmaI fragment of the HNF1 cDNA, in which the first 33 amino acids are removed and 59 extra amino acids encoded in the second phase are added in C-terminal, retained only $1-2 \%$ of the wild type activity (deletion $\mathrm{T} 7 \beta \mathrm{H}-34 / 291$; Figure $5 \mathrm{~A}$, lane 9 ). Deletion of 35 amino acids from E18 to T53 encoded by the single XhoI fragment of the HNF1 cDNA led to a complete loss of specific DNA-binding (deletion $T 7 \beta H-\Delta 18 / 53$; Figure $5 A$, lane 10 ). This deletion mutant could bind the PE56 probe with very low efficiency but only in the absence of any competitor DNA (not shown). Finally, the deletion of 175 amino acids from G34 to P208, encoded by the unique Apal fragment of the HNF1 sequence, abolished specific as well as nonspecific DNA-binding activity (deletion $T 7 \beta \mathrm{H}-\Delta 34 / 208$; Figure $5 \mathrm{~A}$, lane 11 and data not shown).

Thus, the HNF1 homeodomain appeared to be unable to stably bind DNA by itself and the question arose as to whether it would need to dimerize to do so, since dimers of native HNF 1 had been observed as discussed above. This prompted us to analyse, by band-shift assay, the ability of the different deletion mutants to form DNA-bound heterodimers with the co-translated wild type protein. In addition, in order to analyse dimerization independantly of DNA binding, we ran the same mutants on SDSpolyacrylamide gels in nonreducing conditions, thus taking advantage of the potential spontaneous $S-S$ bond formation between two HNF1 monomers.

The first two C-terminal deletion mutants presented, on nonreducing SDS gels, the variations in mobility that were expected for truncated HNF1 homodimers (Figure 5B, lanes $15-17$ ), thus confirming the observations made with the native protein. Co-translation of wild-type HNF1 with those mutants revealed heterodimers by both techniques (Figure 5A, lanes 17 and 18 and $5 B$, lanes 23,24 ). As mentioned above, deletion of the putative recognition helix abolished DNA binding, thus making it impossible to check by band-shift analysis whether or not the resulting mutant could dimerize. In fact, it could still form homodimers and more clearly heterodimers which were visualized on a SDS-polyacrylamide gel (Figure 5B: lanes 18 and 25 ). Thus, it appeared that amino acids C-terminal to the V264 were not required for HNFl dimerization.

In contrast, the three deletions in the $\mathrm{N}$-terminal domain strongly reduced or abolished both DNA-binding and dimerization, although in different manners. First, as mentioned above, the $T 7 \beta \mathrm{H}-\Delta 18 / 53$ deletion mutant lost the ability to bind specifically to the HNF1 DNA target site; it also failed to form heterodimers with the intact protein in both the DNA binding assay and SDS PAGE in nonreducing conditions (figure 5A, lanes 10 and 21 ; figure 5B, lanes 20 and 27). It should be noted however, that the deletion of C50 makes the method irrelevant 
A

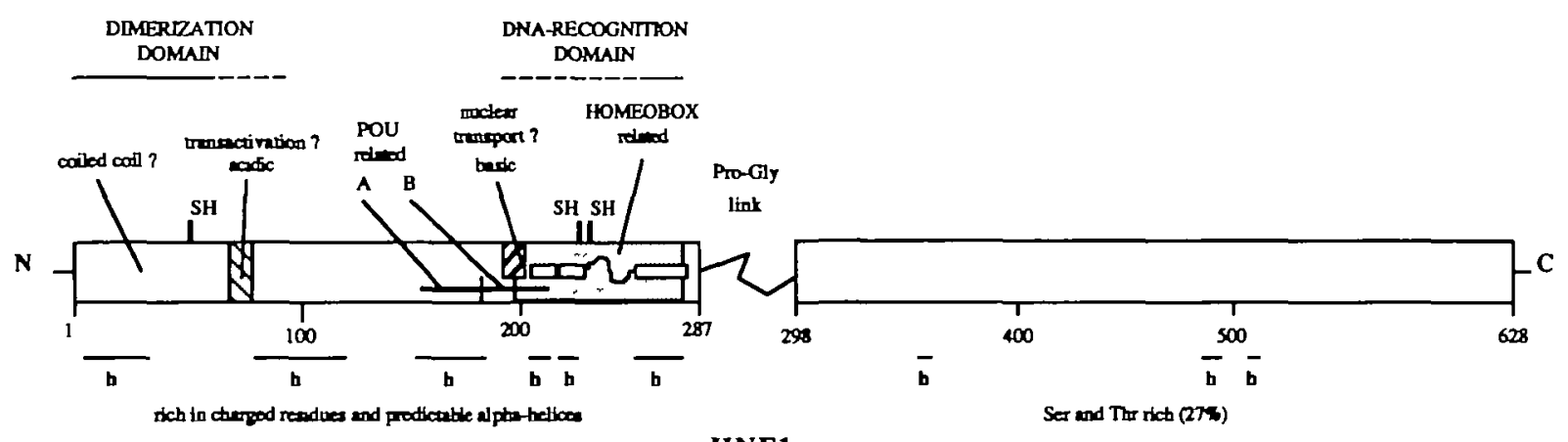

HNF1

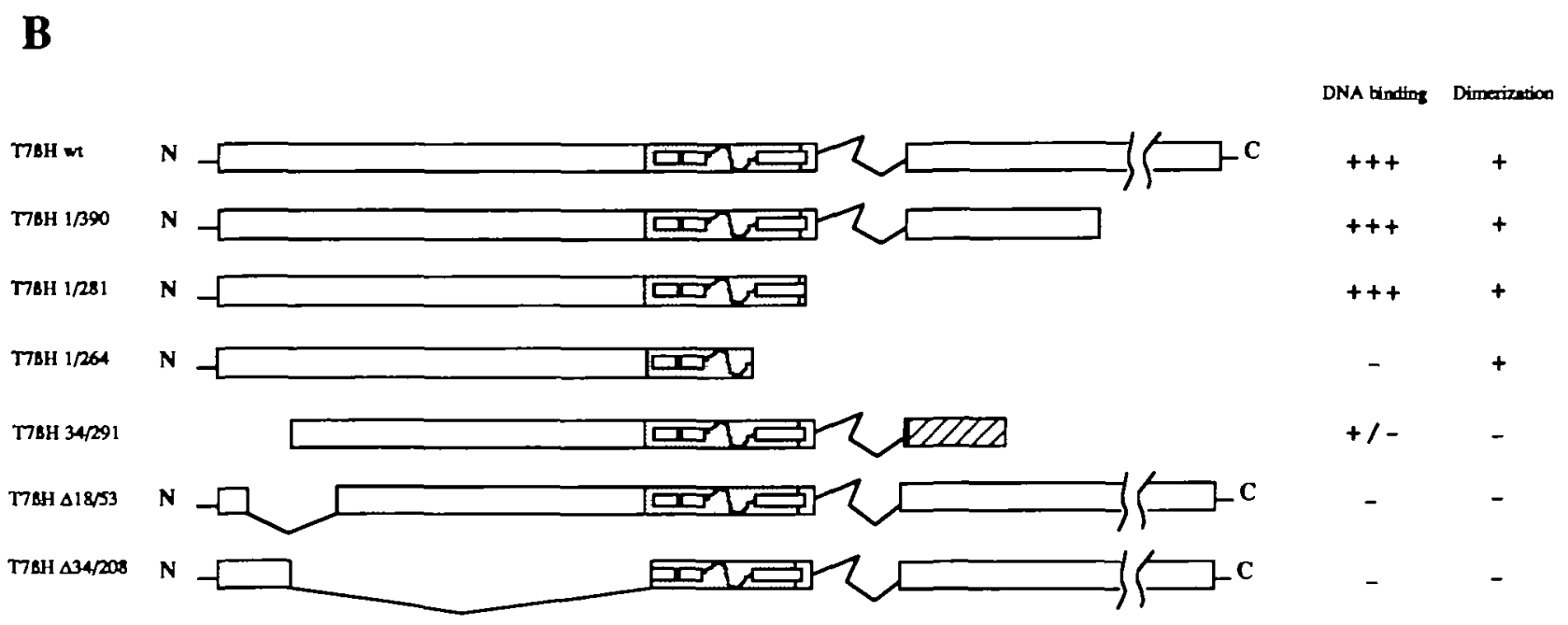

Figure 6A: Global architecture of the HNFI protein. The domains discussed in the text are represented by boxes or bars linearly arranged along the sequence, given by the amino acid numbers used in the Figure 4 . Motifs that might be involved in transactivation and nuclear transport (according to 33 and 34 resp) correspond to amino acids E71-D80 and K197-K207 respectively. SH indicate cysteine residues. N and C indicate the N- and C-terminal parts of the protein. Segments more than 3 amino acid long that were predicted as $\alpha$-helical using the algorithm of Garnier et al. (35) are indicated by horizontal bars with an $h$ letter beneath. The three helices and the 24 amino acid loop present in the HNF1 with a loop model of homeobox are also represented (see text and Figure 7). B: Deletion analysis of the HNFI DNA binding domain. The 7 constructions described in text are schematically represented with same scale as in Figure 6A. Parts of the HNFI with a loop homeodomain that are present in each of them are also represented. A hatched box indicates the 59 extra amino acids, encoded in the second phase, that are C-terminal in the $77 \beta \mathrm{H}-34 / 291$ protein. $\mathrm{N}$ and $\mathrm{C}$ indicate the termınal parts of the wild type HNF1 protein when present in the deletion mutants. Results of Figure 5 are summarized in the right part of the Figure.

for this mutant without precise identification of the cysteine residues involved in S-S bond formation. In any case, these results demonstrated that the homeodomain is not sufficient for specific DNA binding and indicated that formation of the HNF1 dimers requires sequences far from the homeodomain. Second, the residual DNA binding activity observed with T7BH-34/291 suggested that the $\mathrm{N}$-terminal part of the HNF1 dimerization domain (upstream of G34) is still required but perhaps less crucial than the rest of it (which includes some amino acids from G34 to T53). Indeed, the fact that DNA binding is completely lost by $\mathrm{T} 7 \beta \mathrm{H}-\Delta 18 / 53$ and that the $\mathrm{T} 7 \beta \mathrm{H}-34 / 291-$ and T7 $\beta \mathrm{H}-1 / 281-\mathrm{DNA}$ complexes have similar electrophoretic mobilities makes unlikely, though does not exclude, the hypothesis of a monomeric interaction of the HNF1-34/291 molecule with DNA and rather suggests a weak residual ability to dimerize for this mutant. Nevertheless, this mutant did not form heterodimers when co-translated with wild type HNF1 and dimers including it have not yet been detected in nonreducing protein gels (Figure 5A, lane 20 and 5B lanes 19 and 26). It is possible that it dimerizes poorly in the absence of DNA and cannot compete for the dimerization process with the wild type protein, when co-translated. Finally, the third $\mathrm{N}$-terminal deletion $\mathrm{T} 7 \beta \mathrm{H}-\Delta 34 / 208$, which was also unable to dimerize, confirmed that there are some amino acids crucial for dimerization downstream of P33 (Figure 5B, lanes 21, 28). In addition, it had lost any affinity for any type of DNA which, we assume, was retained by $T 7 \beta \mathrm{H}-\Delta 18 / 53$ thanks to an intact homeodomain moiety. This suggested that the N-terminus of the HNF1 homeodomain could lie upstream of A209 (see also discussion below).

\section{DISCUSSION}

The HNF1 DNA-recognition domain is probably not a classical helix-turn-helix motif

To document the homology between the DNA-recognition domain defined above and the homeodomain, we aligned the predicted amino acid sequence of HNF1 in the region of peptide A with 87 of the 60 amino acid-long homeobox motifs compiled to date $(37,38)$. The mean overall homology was approximately 


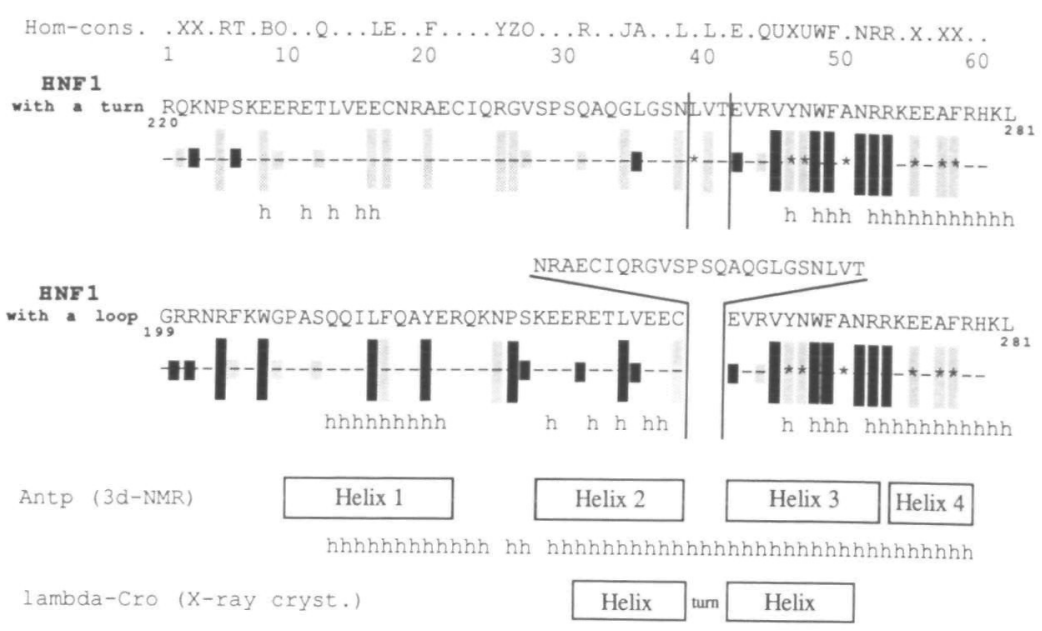

Figure 7: HNF1 homeodomain compared to the homeodomains sequenced to date. The HNF1 with a 3 amino acid tum (residues R220 to H279) and the HNF1 with a 24 amuno acid loop (residues G199 to H279) sequences were aligned separately with the 31 positons where a consensus could be found among more than $60 \%$ of the homeoprotein (hom-cons, 37). Amino acids are single letter coded and 5 additional codes are used for the hom-cons sequence as follows: B= Big hydrophobic i.e. F, Y or $\mathrm{I} ; \mathbf{J}=\mathbf{I}$ or $\mathrm{L} ; \mathbf{O}=\mathrm{T}$ or $\mathrm{S} ; \mathbf{U}=\mathrm{V}$ or $\mathrm{I} ; \mathbf{X}=\mathrm{K}$ or $\mathrm{R} ; \mathrm{Z}=\mathrm{P}$ or $\mathrm{L}$. A diagram below each sequence illustrates the agreement with the consensus as follows: each of the 31 positions conserved in the homeobox consensus sequence is represented by a small or a big bar when between 60 to $80 \%$ or more than $80 \%$ of the homeoproteins agree with the consensus respectively. The bar is black when the corresponding HNFl amino acid is in structural agreement with the consensus and pale when it differs. A star (*) indicates an atypical feature specific to HNFI (see text). Boxes at the bottom indicate the location of helices identified by three-dimensionsl NMR in the Antp homeodomain (40) and by X-ray crystallography in the $\lambda$-Cro helix-tum-helix motif (41). h letters indicate the $\alpha$-helical segments predicted from the HNFI sequences and from the Antp homeobox sequence as a control, according to the algorithm of J. Garnier et al. (35). Numbers below the hom-cons. sequence indicate positions in the canonical homeobox sequence (18). Numbers below the HNF1 sequences indicate positions of their ends in the complete HNF1 amino acid sequence (Figure 4).

$17 \%$, clearly concentrated in the third helix. As recently proposed by Finney (39), allowing the looping out of 24 amino acids ('HNF1 with a loop') in the place of the canonical 3 amino acid turn ('HNF1 with a turn') between helices II and III in the HNF1 sequence led to significant improvement in homology (mean: $23 \%$ ).

Figure 7 illustrates the degree of structural homology between the HNF1 sequence, in both configurations discussed here, with the consensus for the homeodomain (see criteria adopted in legend). The homology is clearly restricted to the third helix in the case of HNF1 with a turn and extends largely to the whole $\mathrm{N}$-terminal region in the case of HNF1 with a loop. Moreover, predicted $\alpha$-helices, using the algorithm that gave the best result with the Antp sequence, as compared to available structural data (40), perfectly match those of the Antp homeodomain in the case of HNF1 with a loop while they are hardly compatible in the case of HNF1 with a turn.

If further structural analysis were to confirm the validity of the HNF1 with a loop model, one might wonder about the exact nature of the selective pressure that led to an almost universal conservation of a strict 3 amino acid turn among the helix-turnhelix proteins and about the properties of the loop that allowed HNF1 to escape this selection.

Proteins of a new family, including two that are mammalian transcription factors restricted to a specific cell type, share a highly homologous homeobox and two sequences upstream of it, defined as 'POU-A' and 'POU-B' (see references 38, 42 and 43 for review). The two latter show some homology with the HNF1 sequence, however it is very weak (highest scores : 6/26 and $4 / 34$ respectively) as compared to homologies between the already described POU proteins themselves $(42,38)$. Moreover, these sequences overlap the HNF1 homeodomain whereas they are separated by roughly $20-30$ amino acids in POU proteins $(42,38)$.
Further careful examination shows that several amino acids of the segment corresponding to the putative DNA-recognition helix in the HNF1 sequence differ radically in their nature from those found in most if not all other homeobox sequences (37). These positions are outlined as stars $\left(^{*}\right)$ in Figure 7 . Let us retain two features that are exclusive to HNF1: An alanine at position 50 : the residue in this position is believed to determine the specificity of DNA-recognition of homeoboxes of the Antp subclass $(44,45)$. At this key position most known homeoboxes contain a glutamine (the other residues that have been found until now are $\mathrm{K}, \mathrm{C}, \mathrm{S}, \mathrm{H}, \mathrm{I}$ ). An aliphatic residue at this location may seriously impair binding to DNA through hydrogen bonding or polar interactions which might explain why HNF1 should bind to DNA as a dimer. A glutamic acid and an alanine at positions 55 and 57 respectively: all known homeoproteins have an arginine or a lysine at these extremely conserved functional positions and almost all at the adjacent position 58 also. The replacement, exclusive to HNF1, of these three basic residues by one acidic and two hydrophobic ones is striking, since these amino acids have been recently demonstrated to be exposed on the external face of the fourth helical segment of the Antp homeodomain and proposed to be involved in general electrostatic contacts with DNA (40); they are usually taken as a distinctive character of all homeoproteins (43). More precise mutagenesis is needed to define which amino acids in the long third helix of HNFI are involved in contacting DNA, since they are likely to differ from those of both the canonical homeodomain and prokaryotic helixturn-helix motif, possibly in relation to the presence of the 24 amino acid loop.

The HNF1 DNA-binding domain includes a distal dimerization domain of new type

The similarities and differences between HNFI and other homeoproteins prompted us to compare the HNF1 target site to 
other homeoprotein binding sequences determined to date. Homeoprotein DNA binding sites are AT-rich and similar to the average consensus sequence for one half of the HNF1 palindromic binding site (not shown). However, two points should be mentioned: first, except in yeast, homeoprotein target sites identified so far lack dyad symmetry; second, the HNFl monomer has never been shown to form a stable complex with DNA. Rather, taken together, the different experiments reported here, using both native and cloned HNF1, strongly suggest that HNF1 forms homodimers, in the absence of DNA as well as when bound to its DNA target and that dimerization is essential for specific and high affinity DNA-binding. A domain required for dimerization lies outside of the homeodomain in a distal $\mathrm{N}$ terminal region of the HNF1 protein. This region is rich in predicted $\alpha$-helical structures and shows remote homologies with sequences involved in coiled coil formation but is not included in any existing dimerization motif family (not shown). During revision of our manuscript, anoter group outlined the crucial role of the N-terminal segment of HNF1 for dimerization and DNAbinding (48) An N-terminal dimerization domain was also observed in the Mat- $\alpha 2$ homeoprotein (46) to which it confers a very interesting flexibility in its interactions both with DNA and with other proteins $(46,47)$. Mat- $\alpha 2$ dimers are like here stabilized in vitro in nonreducing conditions, the physiological relevance of which is unknown. The need to dimerize for DNAbinding has so far been observed with no other homeoprotein. By contrast, this property is shared by most of the prokaryotic factors of the $\lambda$-Cro-type (41).

\section{HNF1 properties extend the field of the homeoprotein superfamily}

The example of HNF1, in addition to that of the POU proteins, further documents the homeodomain as the DNA recognition moiety of transcription factors implicated in the control of cell specific genes (43). As we discussed before, several predicted structural features extend the properties encountered among homeoproteins; this is also true at the functional level. HNF1 was initially identified only in hepatic nuclear extracts $(8-11)$, however, northern blot and in situ hybridization showed that HNF1 transcripts are present at high levels in nonhepatic tissues like intestine and kidney ( 32 and our unpublished observations). On the other hand, expression of exogenous HNF1 is not sufficient to drive a high rate of transcription of a co-transfected albumin promoter in several cell types ( $F$. Tronche, unpublished results). Thus, achievement of tissue specific patterns of transcription does not appear to be based on the action of strictly tissue specific trans-acting factors, but rather on various combinations of a small number of proteins. Homeoproteins, like HNF1, might fulfill complex regulation networks by alternative homo- or hetero-dimerizations and the low specificity observed in DNA recognition by the homeoproteins might be overcome by specific protein-protein interactions.

\section{ACKNOWLEDGEMENTS}

We are grateful to $S$. Hirai and $B$. Arcangioli for advice in protein purification, to $S$. Pochet for providing primed affinity resin, to J. Van Damme and M. Puype for their help in protein blotting and amino acid sequence analysis, to $F$. Tronche for help in construction of pRSV-HNF1, to R. Treisman for the gift of T7- $\beta$ globin vector, to J. Ars for typing, to N. Dostatni, R. Sousa, $\mathrm{J}$. Ham and $\mathrm{M}$. Weiss for valuable comments on the manuscript.
This work was supported by grants from the EEC BAP Program, from the ARC, the LNFCC, and the FMRF to M.Y. and from the Belgian National Fund for Scientific Research (N.F.W.O.) to J.V. I.B. was supported by a Boehringer Ingelheim Fonds fellowship.

\section{REFERENCES}

1. Corski, K., Carneiro, M. and Schibler, U. (1986) Cell, 47, 767-776.

2. Heard, J.M., Herbomel, P., Ott M.O., Mottura-Rollier, A., Weiss, M. and Yaniv, M. (1987) Mol. Cell. Biol., 7, 2425-2434.

3. Cereghuni, S., Raymondjean, M., Garcia Carranca, A., Hertomel, P. and Yaniv, M. (1987) Cell, 50, 627-638.

4. Lichsteiner, S., Wuarin, J. and Schibler, U. (1987) Cell, 51, 963-973.

5. Babiss, L.E., Herbst, R.S., Benne, A.L. and Damell, Jr., J.E. (1987) Genes and Develpment, 1, 256-267.

6. Herbomel, P., Rollier, A., Tronche, F., Ott, M.O., Yaniv, M. and Weiss, M. (1989). Mol. Cell. Biol., 9, 4750-4758.

7. Tronche, F., Rollier, A., Bach, I., Weiss, M. and Yaniv, M. (1989) Mol. Cell. Biol., 9, 4759-4766.

8. Courtois, G., Morgan, J.G., Campbell, L.A., Fourel, G. and Crabtree, G.R. (1987). Science, 238, 688-692.

9. Hardon, E.M., Frain, M., Paonessa, G. and Cortese, R. (1988). EMBO J., 7, 1711-1719.

10. Schorpp, M., Kugler, W., Wagner, U. and Ryffel, G.U. (1988). J. Mol. Biol., 202, 307-320.

11. Cereghini, S., Blumenfeld, M. and Yaniv, M. (1988). Genes and Development, 2, 957-974.

12. Courtois, G., Baumhueter, S. and Crabtree, G.R. (1988). Proc. Nall Acad. Sci. USA, 85, 7937-7941.

13. Blumenfeld, M., Cereghini, S., Raymondjean, M., Chouard, T. and Yaniv, M. (1988). UCLA symposia on Molecular and Cellular Brology, New Series, Vol.95, Alan R. Liss Inc., New York, NY, 91-105.

14. Monaci, P., Nicosia, A. and Cortese, R. (1988) EMBO J., 7, 2075-2087.

15. Ryffel, G.U., Kugler, W., Wagner, U. and Kaling, M. (1989) Nucl. Acids Res., 17, 939-953.

16. Maire, P., Wuarin, J. and Schibler, U. (1989) Science, 244, 343-346.

17 Lichtsteiner, S. and Schibler, U. (1989) Cell, 57, 1179-1187.

18. Arcangiolı, B., Pochet, S., Sousa, R.M. and Huynh-Dinh, T. (1989) Europ. J. Biochem., 179, 359-369.

19. Laemmli, U.K. (1970) Narure, 227, 680-685

20. Bauw, G., de Loose, M., Inge, D., Van Montagu, M. and Vandekerckhove, J. (1987). Prac. Nall. Acad. Sci. USA, 84, 4806-4810.

21. Saiki, R.K., Gelfand, D.H., Stoffel, S., Scharf, S.J., Higuchi, R., Horn, G.T., Mullis, K.B. and Ehrlich, H.A. (1988) Science, 239, 487-491.

22. Maniatis, T., Fritsch, E.F. and Sambrook, J. (1982) Molecular cloning: a laboratory manual (Cold Spring Harbor, New york).

23. Sanger, F., Nicklen, S. and Coulson, A.R. (1977) Proc. Natl Acad. Sci. USA, 74, 5463-5467.

24. Chen, C. and Secburg, P. (1985). DNA, 4, 165-170.

25. Gorman, C.M., Merlino, G.T., Willingham, M.C., Pastan, I. and Howard, B.H. (1982). Proc. Narl. Acad. Sci. USA, 79, 6777-6781.

26. Chimgwin, J.M., Przybyla, A.E., Mac Donald, R.J. and Rutter, W.J. (1979) Biochemistry, 18, 5294-5299.

27. Baumhueter, S., Courtois, G. and Crabtree, G.R. (1988) EMBO J., 7, 2485-2493.

28. Deschatrette, J. and Weiss, M.C. (1974) Biochimie, S6, 1603-1611.

29. Ryseck, R.P., Hirai, S.I., Yaniv, M. and Bravo, R. (1988) Nature, 334, 535-537.

30. Bimsteil, M., Busslinger, M. and Strub, K. (1985) Cell, 41, 349-359.

31. Frain, M., Swart, G., Monaci, P., Nicosia, A., Stämpfli, S., Frank, R. and Cortese, R. (1989) Cell, 59, 145-157.

32. Baumhueter, S., Mendel, D.B., Conley, P.B., Kuro, C.J., Turk, C., Graves, M.K., Edwards, C.A., Courtois, G. and Crabtree, G.R. (1990). Genes and Developmen, 4, 372-379.

33. Ptashne, M. (1988) Narure, 335, 683-689.

34. Dingwall, C. and Laskey, R.A. (1986) Ann. Rev. Cell. Biol., 2, 367-390.

35. Gamier, J., Osguthrope, D. and Robson, B. (1978) J. Mol. Biol, 120, $97-120$.

36. Gehring, W.J. (1987) Science, 236, 1245-1251.

37. Scott, M.P., Tamkun, J.W and Hartzell, GW.III (1989) BBA Rev., 989, 25-48.

38. He, X., Treacy, M.N., Simmons, D.M., Ingraham, H.A., Swanson, L.W. and Rosenfeld, M.G. (1989) Narure, 340, 35-42. 
39. Finney, M. (1990). Cell, 60, 5-6.

40. Qian, Y.Q., Billeter, M., Oting, G., Müller, M., Gehring, W.J. and Würrich, K. (1989) Cell, 59, 573-580.

41. Pabo, C.O. and Sauer, R.T. (1984) Ann. Rev. Biochem., 53, 293-321.

42. Herr, W., Sturm, R., Clerc, R.G., Corcoran, L.M., Baltimore, D., Sharp, P.A., Ingraham, H.A., Rosenfeld, M.G., Finney, M., Ruvkun, G. and Horvitz, H.R. (1988) Genes and Development, 2, 1513-1516.

43. Levine, M. and Hoey, T. (1988) Cell, 55, 537-540.

44. Hanes, S.D. and Brent, R. (1989) Cell, 57, 1275, 1283.

45. Treisman, J., Gönczy, P., Vashishta, M., Harris, E. and Desplan, C. (1989) Cell, 59, 553-562.

46. Sauer, R.T., Smith, D.L. and Johnson, A.D. (1988) Genes and Development, 2, $807-816$.

47. Keleher, C.A., Goutte, C. and Johnson, A.D. (1988) Cell, 53, 927-936.

48. Nicosia, A., Monac1, P., Tomei, L., De Francesco, R., Nuzzo, M., Stunnenberg, H. and Cortese, R. (1990) Cell, 61, 1225-1236. 